\title{
Microbial decolorization of mixture of dyes by an application of laccase through bacillus subtillis ETL-I 979 isolated from soil of industrial effluent treatment plant
}

\begin{abstract}
The strain bacillus subtillis. ETL-1979 exhibiting laccase activity was screened from industrial effluent treatment plant. The M9 medium containing $\mathrm{Cu} 2+$ was used for enriching and isolating bacterial strains capable of oxidizing syringaldazine. One isolated strain was identified as Bacillus subtilis ETL-1979 based on the results of physiological and biochemical tests and $16 \mathrm{~S}$ rDNA sequence analysis. The strain ETL-1979 could grow at temperatures ranging from 20 to $55^{\circ} \mathrm{C}$ and showed optimum growth temperature and $\mathrm{pH}$ at $25^{\circ} \mathrm{C}$ and 7.0 , respectively. The sporulation rate of the strain clearly correlated well with the laccase activity. The temperature half-life of the spore laccase was $2.5 \mathrm{~h}$ at $80^{\circ} \mathrm{C}$ and the $\mathrm{pH}$ half life time was $15 \mathrm{~d}$ at $\mathrm{pH} 9.0$. Its spore laccase could decolorize $50-90 \%$ of Remazol brilliant blue R (RBBR), alizarin red, congo red, methyl orange and methyl violet, which suggests the potential application of spore laccase in dyestuff treatment.
\end{abstract}

Keywords: bacterial laccase, bacillus subtilis, spore, decolorization
Volume 4 Issue 4 - 2017

\author{
Maulin P Shah \\ Industrial Waste Water Research Laboratory, India
}

Correspondence: Maulin P Shah, Industrial Waste Water Research Laboratory,Applied \& Environmental Microbiology Lab, Enviro Technology Limited (CETP), Plot No: 24/3/2414, GIDC, Ankleshwar- 393 002, Gujarat, India, Emailshahmp@beil.co.in

Received: December 14, 2016 | Published: April 17, 2017

\section{Introduction}

Laccases (benzenediol: oxygen oxidoreductases, EC1. 10.3.2) are multi-copper proteins that can oxidize a wide range of inorganic and aromatic compounds, particularly phenols, while reducing molecular oxygen to water. ${ }^{1}$ Laccases catalyze the removal of a hydrogen atom from phenolic substrates and aromatic amines by one-electron abstraction. The free radicals formed during the reaction are also capable of undergoing further depolymerization, repolymerization, demethylation or quinone formation. ${ }^{2-4}$ The low substrate specificity of laccases and their ability to oxidize many pollutants suggest their industrial and biotechnological applications. ${ }^{5,6}$ Laccases are widely distributed among fungi and plants. ${ }^{7}$ However, it has been found that laccases are also widespread among bacteria. ${ }^{1}$ To date, laccases have mostly been isolated and characterized from plants and fungi but only fungal laccases are used currently in biotechnological applications. In contrast, only a few bacterial laccases have been characterized. Bacterial laccases could oxidize syringaldazine and 2,6-dimethoxyphenol, which are typical substrates for laccases, and also possess the canonical four copper-binding domains. Nervertheless, the overall sequences of bacterial laccases show little similarity with fungal laccases. Therefore, they are often known as "multicopper oxidase" or "(poly) phenol oxidase", and their activity is usually defined as "laccase-like". ${ }^{8}$ The first report on bacterial laccase was from the non-motile strain of Azospirillum lipoferum isolated from rice rhizosphere. ${ }^{9}$ This enzyme was identified as a laccase by using a combination of substrates and inhibitors. ${ }^{1,10}$ Laccases activities were also found in Bacillus sphaericus, ${ }^{11}$ Escherichia coli, ${ }^{12}$ Bacillus halodurans ${ }^{13}$ and Streptomyces, Psammoticus. ${ }^{14}$ CotA, which is the endospore coat component of Bacillus subtilis, is the most-studied bacterial laccase. ${ }^{15}$ Since spores allow microorganisms to survive under drastic conditions, spore coat enzymes might also withstand high temperatures or extreme $\mathrm{pH}$ values. Since most fungal laccases are unstable at $\mathrm{pH}$ values higher than 7.0, their detoxification efficiencies for pollutants often decrease under alkaline conditions. This limits the industrial potential of fungal laccase as many processes are performed in alkaline conditions. Alternatively, spore laccases which are active in the alkaline $\mathrm{pH}$ range could be used for bioremediation or application in membrane reactors. ${ }^{4}$ Compared with fungal laccases, bacterial laccases have the advantages of being less sensitive towards halides and alkaline conditions as well as a fast growth rate. ${ }^{16}$ Despite the importance of bacterial laccase in pollutant degradation, only a few novel bacterial strains displaying "laccase-like" activity have been discovered. The lack of a commercially available robust and inexpensive laccase is a major barrier to the widespread application of laccases in various industrial sectors. ${ }^{17}$ Since bacterial genetic tools and biotechnological processes are well established, developing bacterial laccases would be significantly important. ${ }^{18}$ The present study was carried out to isolate and characterize the bacteria strain Bacillus sp. ETL-1979 exhibiting laccase activity from soil of industrial effluent treatment plant. The spore laccase of this strain was characterized and used to decolorize several synthetic dyes.

\section{Materials and methods}

\section{Sample collection}

The soil samples used in the present study were collected from textile effluent samples from textile industry, Ankleshwar, Gujarat, India. Collected soil samples were stored aerobically at $4^{\circ} \mathrm{C}$. 


\section{Isolation of microorganisms}

For isolation and enrichment of laccase-producing bacterial strains, the 250-ml flasks containing $100 \mathrm{ml}$ M9 culture medium supplemented with $0.2 \mathrm{mmol} / \mathrm{l} \mathrm{Cu} 2+$ were inoculated with $10 \mathrm{~g}$ of soil particles and incubated at $37^{\circ} \mathrm{C}$ on a rotary shaker (130rpm) for 2days. Then $5 \mathrm{ml}$ cultures were transferred to $100 \mathrm{ml}$ Luria-Bertani (LB) culture medium containing $0.2 \mathrm{mmol} / 1 \mathrm{Cu} 2+$ and incubated at $37^{\circ} \mathrm{C}$ at $130 \mathrm{rpm}$ for 7 days. Stable enrichment cultures were obtained after subculture. To isolate pure cultures, the enriched cultivated products were appropriately diluted with sterile saline solution $(0.9 \% \mathrm{NaCl})$ before spreading onto $\mathrm{LB} / \mathrm{Cu} 2+$ plates. The plates were incubated at $37^{\circ} \mathrm{C}$ for 3 days. Individual bacterial colonies from the plates were dropped with $0.1 \%(\mathrm{~m} / \mathrm{v})$ syringaldazine for checking laccase activity. The colonies displaying pink were streaked on new $\mathrm{LB} / \mathrm{Cu} 2+$ plates for purification. Re-inoculation was performed after identification with syringaldazine as described above. The isolation process was repeated several times until the isolates were found to be pure.

\section{Characterization}

Gram staining was performed according to standard protocol. Gram's characteristics and cell morphology of the isolated strain were determined by microscopy. For carbon sources utilization, the pure cultures were inoculated respectively into peptone-water culture medium containing $1 \%$ substrates, and incubated at $37^{\circ} \mathrm{C}$ for $24 \mathrm{~h}$. The results were determined by the variation of both the turbidity and the color of the culture medium. Control tubes contained uninoculated medium and were incubated at the same conditions. Some biochemical metabolic ability was determined by inocula-ting isolates onto selective media such as casein, urea, balsam and starch agar, to identify protease, urase, lipase and amylase producers, respectively. All assays were carried out in triplicate.

\section{Molecular characterization}

Bacterial cells were collected by centrifugation at $10,000 \mathrm{rpm}$ for $2 \mathrm{~min}$ and incubated with $100 \mu \mathrm{g} / \mathrm{ml}$ lysozyme at $37^{\circ} \mathrm{C}$ for $1 \mathrm{~h}$ followed by the treatment of lysis solution ( $1 \% \mathrm{SDS}, 1 \mathrm{mmol} / \mathrm{LEDTA}, 20 \mathrm{mmol} / 1$ $\mathrm{CH} 3 \mathrm{COONa}$ and $40 \mathrm{mmol} / 1$ Tris-HCl, $\mathrm{pH} 8.0$ ). After adding $5 \mathrm{mmol} / 1$ $\mathrm{NaCl}$ into the lysis solution, the mixture was extracted with phenol/ chloroform/isoamyl alcohol (25:24:1). The supernatant was collected and then precipitated by absolute ethanol. The obtained genomic DNA was dissolved in sterile deionized water and stored at $-20^{\circ} \mathrm{C}$ for further use. For polymerase chain reaction (PCR), primers specific for eubacterial 16S rDNA 27F: 5'-GAGTTTGATCMTGGCTCAG-3' $(\mathrm{M}=\mathrm{A}+\mathrm{C}), \quad$ 1492R: 5'-TACGGYTACCTTGTTACGACTT-3' $(\mathrm{Y}=\mathrm{C}+\mathrm{T})$ were used. ${ }^{19}$ The PCR was run in a Gene Amp PCR system 9700 (Applied Biosystems, Singapore). The amplification reaction consisted of an initial denaturation at $93^{\circ} \mathrm{C}$ for $5 \mathrm{~min}$, followed by 30 cycles of $94^{\circ} \mathrm{C}$ for $18 \mathrm{~s}, 56^{\circ} \mathrm{C}$ for $15 \mathrm{~s}$ and $72^{\circ} \mathrm{C}$ for $78 \mathrm{~s}$, and a final extension step at $72^{\circ} \mathrm{C}$ for $7 \mathrm{~min}$. The PCR products were analysed by electrophoresis in $1.0 \%(\mathrm{w} / \mathrm{v})$ agarose gel and photographed using Bio Imaging System (Gene Genius, USA). Amplification products were cloned using a commercially avail-able pMD18-T vector cloning kit and transformed into competent E. coli JM109. Positive clones were identified by PCR amplification with above primer pairs.

\section{Nucleotide sequencing, alignment and phylogeny}

16S rDNA sequencing of the isolated strain was done by Bangalore Genei Company, India. Related sequences were obtained from the GenBank database using the Basic Local Alignment
Search Tool (BLAST) search program. Multiple sequences alignment was performed using Clustal X 1.81. Phylipwx package was used to calculate similarity values and construct a phylogenetic tree.

\section{Optimization of growth conditions}

The optimal growth conditions with regard to $\mathrm{pH}$ and temperature were determined. The strain was inoculated in LB medium with varying $\mathrm{pH}$ values $(4-11)$ and incubated at $15-55^{\circ} \mathrm{C}$. The optical density of the growing cultures was observed at $600 \mathrm{~nm}$ using UV1800 spectrophotometer (Shimzadzu, Japan) to determine the optimum growth conditions. All assays were carried out in triplicate.

\section{Effect of metals and saline solution on bacterial growth}

To study the effect of metals on growth, $200 \mu \mathrm{g} / \mathrm{ml} \mathrm{Zn2+,} \mathrm{Fe3+,}$ $\mathrm{Ca} 2+, \mathrm{Mn} 2+, \mathrm{Mg} 2+$ or $\mathrm{Cu} 2+$ was supplemented in $\mathrm{LB}$ culture medium, respectively. Cultures were grown in $25 \mathrm{ml}$ medium in $100 \mathrm{ml}$ conical flasks at $37^{\circ} \mathrm{C}$ for $24 \mathrm{~h}$. Culture grown in absence of metal was used as a control. Growth was determined by measuring the absorbance at $600 \mathrm{~nm}$ against blank. The strain was inoculated in LB medium supplemented with $1,2,4,6,8,10$ or $12 \% \mathrm{NaCl}$. The turbidity of the growing cultures was observed at $600 \mathrm{~nm}$ using UV1800 spectrophotometer (Shimzadzu, Japan) to determine the growth status. All assays were carried out in triplicate.

\section{Sporulation rate and laccase activity relationship}

B. subtilis ETL-1979 was inoculated on LB plates containing $0.2 \mathrm{mmol} / 1 \mathrm{Cu} 2+$ and incubated at $30^{\circ} \mathrm{C}$. The quantities of the spore were calculated everyday and the laccase activity was determined at the same time. The sporulation rate was determined by the percentage of the quantities of spore opposite to all cells. The spores were removed from the agar with $1 \mathrm{~mol} / 1 \mathrm{KCl}$, washed with $0.5 \mathrm{~mol} / 1 \mathrm{NaCl}$, and re-suspended in $0.1 \mathrm{~mol} / 1$ citrate-phosphate buffer $(\mathrm{pH} 6.8)$. The spore suspension was prepared for laccase activity determination. All assays were carried out in triplicate for each sample.

\section{Spore laccase activity assay}

Spore laccase activity was determined at $40^{\circ} \mathrm{C}$ using syringaldazine (dissolved in absolute ethanol, Sigma) as the substrate. The oxidation of syringaldazine was detected by measuring the absorbance increase at $525 \mathrm{~nm}\left(\varepsilon 525=65 \mathrm{mmol}^{-1} \mathrm{Lcm}^{-1}\right)$ after $3 \mathrm{~min}$ using a spectrophotometer (UV-1800 spectrophotometer, Shimzadzu, Japan). The reaction mixture $(3 \mathrm{ml})$ contained $100 \mu$ l of spore suspension (10mg wet spores), $2.4 \mathrm{ml}$ of citrate-phosphate buffer $(0.1 \mathrm{~mol} / \mathrm{L}, \mathrm{pH}$ 6.8 ), and $0.5 \mathrm{ml}$ of $0.5 \mathrm{mmol} / \mathrm{L}$ syringaldazine. One unit of enzyme activity was defined as the amount of enzyme required to oxidize $1 \mu \mathrm{mol}$ of substrate perminute. All assays were carried out in triplicate for each sample. Standard deviation did not exceed $5 \%$ of the average values.

\section{Effect of $\mathrm{pH}$ and temperature}

Determination of the optimum $\mathrm{pH}$ was conducted in $0.1 \mathrm{~mol} / 1$ citratephosphate buffer in the range of $\mathrm{pH} 4.0-8.0$ using syringaldazine as the substrate. The optimum temperatures of the spore laccase were determined over the range of $0-100^{\circ} \mathrm{C}$ with syringaldazine as the substrate at their optimum $\mathrm{pH}$ values. All assays were carried out in triplicate. Thermal stability of the spore laccase was determined by pre-incubation of $0.1 \mathrm{~mol} / \mathrm{L}$ citrate-phosphate buffer (optimum $\mathrm{pH}$ ) of spores at 60 and $80^{\circ} \mathrm{C}$ and the remaining activity was measured with the assay described above. The $\mathrm{pH}$-stability was examined similarly at 
$30^{\circ} \mathrm{C}$ in different buffers ranging from $\mathrm{pH} 4.0$ to 9.0. All assays were carried out in triplicate.

\section{Determination of dye decolorization efficiency}

The general dyes, remazol brilliant blue $\mathrm{R}$ (RBBR), alizarin red, congo red, methyl orange and methyl violet, were prepared individually with the concentration of $25 \mathrm{mg} / 1$ in sterilized distilled water. The prepared dye solution was supplemented with $100 \mathrm{~g} / 1$ spores and incubated at $37^{\circ} \mathrm{C}$ under mild shaking conditions for 5days. Dye samples without spores were given the same treatment as the control. The absorption spectrum of each dye between 200 and $800 \mathrm{~nm}$ was measured with a UV-1800 spectrophotometer (Shimadzu, Japan). Dye decolorization was assessed by the decrease in absorbance under the maximum wavelength of the dye. All assays were carried out in triplicate.

\section{Results}

\section{Isolation of bacterial strain with high laccase activity}

One hundred foutry colonies were screened from cultures in M9 medium supplemented with $0.2 \mathrm{mmol} / 1 \mathrm{Cu} 2+$. After secondary screening, 46 bacterial strains were picked out by color development reaction to syringaldazine. One of the potential strains showing a high level of laccase activity was named ETL-1979 and selected for further studies. The strain, ETL-1979, that formed pinkish colonies on LB agar plate, was a gram-positive, spore forming, rod shaped, $1-2 \mu \mathrm{m}$ long, motile bacterium, and formed white colonies on LB agar supplemented $0.2 \mathrm{mmol} / \mathrm{l} \mathrm{Cu} 2+$. The optimum $\mathrm{pH}$ was 7.0 and the optimum temperature was observed at $25^{\circ} \mathrm{C}$, though they were able to grow at temperatures ranging from $20-55^{\circ} \mathrm{C}$. The obtained $16 \mathrm{~S}$ rDNA PCR product was about $1.5 \mathrm{~kb}$ in length (Figure 1). The morphological, physiological, biochemical characteristics (Table 1) and the comparative analysis of DNA sequence with available database showed that WD23 was close to the members of B. subtilis. The highest sequence similarity $(100 \%)$ and phylogeny based on Clustal X indicated that the strain ETL-1979 was B. subtilis (Figure 2).

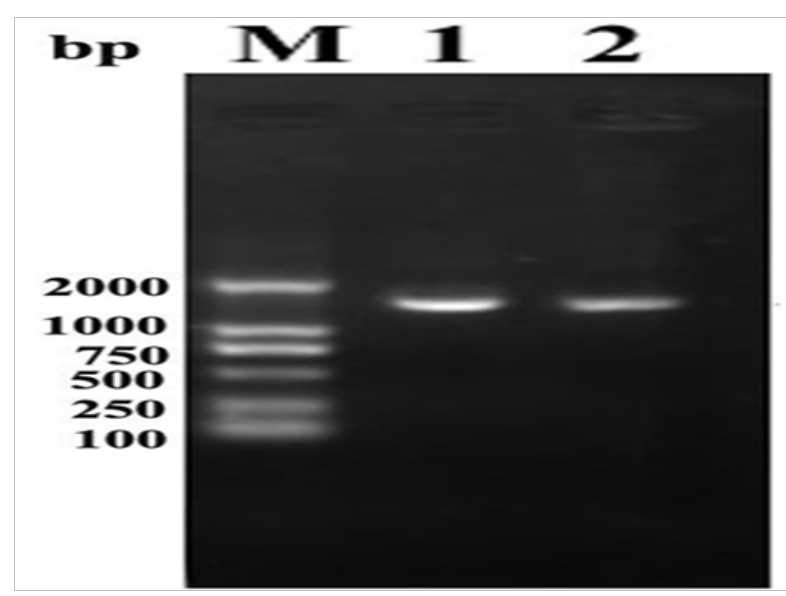

Figure I PCR product of I6S RDNA of B. subtillis ETL- 1979. Lane M:Molecular weight marker (DL2000), lanes I \& 2: B.subtillis strain.
Table I The morphological and Biochemical characterisitics of B.subtillis ETL1979

\begin{tabular}{ll}
\hline Characteristics & B. Subtillis ETL-1979 \\
\hline Colony diameter & $1-3 \mathrm{~mm}$ \\
Colony color & white \\
Cell morphology & Rod \\
Motility & + \\
Gelatin hydrolysis & + \\
Urase & - \\
Lipase & + \\
Oxidase & + \\
Catalase & + \\
Casein protease & + \\
Amylase & + \\
NO3 reduction to NO2- & + \\
M-R reaction & + \\
V-P reaction & + \\
Utilization of: & + \\
Marmite & + \\
Phaseomannite & + \\
Sorbierite & + \\
L-rnamnose & + \\
Melibiose & + \\
Lactose & + \\
Glucose & + \\
\hline
\end{tabular}

\section{Effect of metals and saline solution on bacterial growth}

Metal cations $\mathrm{Zn} 2+, \mathrm{Fe} 3+, \mathrm{Ca} 2+, \mathrm{Mn} 2+, \mathrm{Mg}+$ and $\mathrm{Cu} 2+(200 \mu \mathrm{g} /$ $\mathrm{ml}$ ) all showed a certain extent of inhibition to the growth of the strain. Among them all, Zn2+ showed the highest degree of inhibition. The strain, ETL-1979, showed strength of tolerance to $10 \% \mathrm{NaCl}$.

\section{The relationship between sporulation rate and laccase activity}

The positive correlation of laccase activity and sporulation percentage was observed during the 10day's cultivation as shown in Figure 3. The result demonstrated that the laccase activity was derived from the spores. 


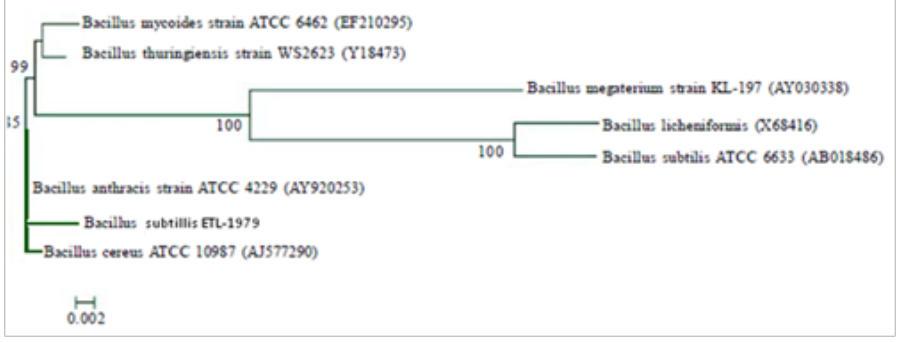

Figure 2 Phylogenetic analysis of I6S rDNA sequences of B. subtilis and related taxa.

\section{Effect of $\mathrm{pH}$ and temperature on the activity and stability of spore laccase}

The optimum $\mathrm{pH}$ of the spore laccase activity was 6.8 and the optimum temperature was observed at $60^{\circ} \mathrm{C}$. The spore laccase exhibited a higher stability in high temperature and alkaline conditions than most fungal laccases. The temperature half-life of the laccase was $2.5 \mathrm{~h}$ at $80^{\circ} \mathrm{C}$. The $\mathrm{pH}$ half life time of the spore laccase was 15 days at $\mathrm{pH} 9.0$.

\section{Efficiency of dye decolorization}

In order to prove the potential application of this bacterium to the treatment of wastewater containing dyestuff, the spore laccase was used for the decolorization of RBBR, alizarin red, congo red, methyl orange and methyl violet. The decolorization rates were $90 \%$ in the treatments of RBBR and alizarin red, and $50-70 \%$ in the treatments of other dyes (Figure 4). These results indicated that the spore laccase could decolorize most dyes efficiently without additional redox mediators.

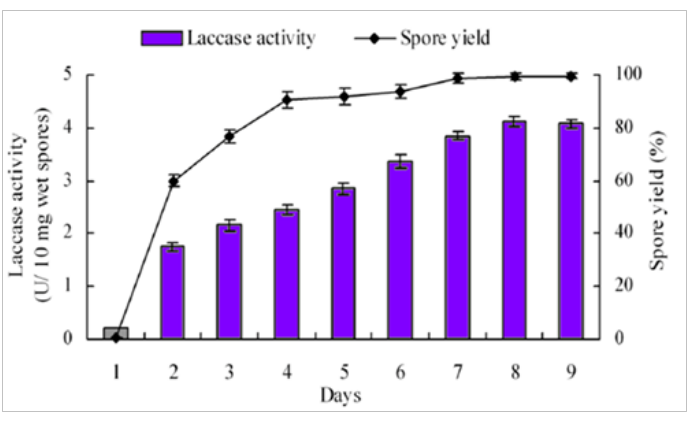

Figure 3 The relationship between sporulation rate and laccase activity of B. subtillis ETL-1979.

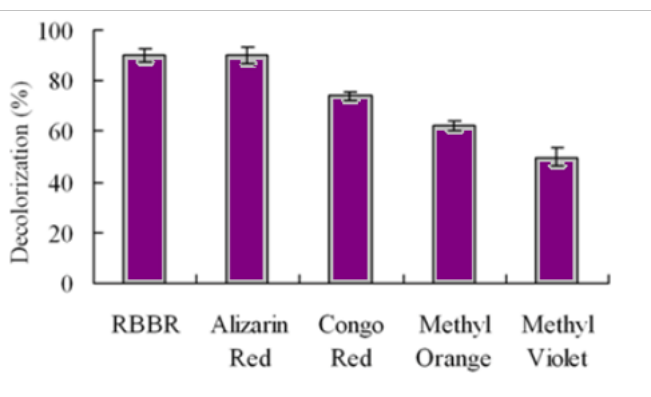

Figure 4 Decolorization of dyes with spore-bound laccase from B. subtillis ETL- 1979.

\section{Discussion}

In the present study, a novel B. subtilis strain ETL-1979 was isolated from industrial effluent treatment plant's soil. This strain was unable to utilize xylose and gum sugar, while the classical strain of $B$. subtilis does according to Bergey`s manual. Unlike other $B$. subtilis strains conserved in our laboratory which show little laccase activity, the strain ETL-1979 exhibits high laccase activity. Therefore, strain ETL-1979 is more valuable for further research. Laccases as biocatalysts have received lots of attention because of their high capacity of oxidizing phenolic and other aromatic compounds. This advantage makes laccases suitable for some biotechnological applications, such as biodegradation of xenobiotic compounds including methoxyphenols, anilines, and benzenethiols. ${ }^{20,21}$ In contrast to fungal laccases, bacterial laccases are highly active and much more stable at high temperatures and high $\mathrm{pH}$ values. As stated above, most wastewaters from textile industries are characterized by a neutral to alkaline $\mathrm{pH}$ (around 7-11). ${ }^{22,23}$ For many industrial applications, it is necessary that the catalysts such as laccases are kept active in the whole process via immobilization or membrane reactors. ${ }^{18}$ Spore laccase of B. subtilis ETL-1979 has a high thermostability and a high stability at alkaline conditions. These characteristics of B. subtilis ETL-1979 may be of significant importance for biotechnological applications. Copper ions were added to the medium during enrichment culture. It is well known that copper ions are toxic even at low concentrations to lots of bacteria. However some bacterial laccases, such as $\mathrm{CueO}$ and PcoA play a role in copper tolerance. ${ }^{24}$ The regulation of copper homeostasis of $E$. coli has been analyzed, although the mechanism is still unclear. ${ }^{25}$ The main mechanism of $\mathrm{CueO}$ in copper resistance has been postulated to be the oxidation of the $\mathrm{Cu}+$ to $\mathrm{Cu} 2+.^{26}$ This process is effective for copper resistance because the $\mathrm{Cu}+$ is more harmful than $\mathrm{Cu} 2+{ }^{27}$ The present study reports that copper resistance of spore protein. B. subtilisETL-1979 can survive in copper-containing medium. However, the strain ETL-1979 is unable to form melaninlike pigment in the medium containing copper ions though $\operatorname{Cot} A$ of $B$. subtilis was associated with the formation of a brownish pigment. ${ }^{28,29}$ The strain, ETL-1979, also showed a strong endurance to high concentrations of $\mathrm{NaCl}$; it can survive in $10 \% \mathrm{NaCl}$. This advantage makes it potentially useful to deal with wastewater containing saline solution and to reduce the time of pretreatment. To date, bacterial laccases have only been found in A. lipoferum, Alteromonas sp. MMB1, Pseudomonas $s p$. KU03, E. coli, and a few species of Streptomyces and Bacillus. There is limited information on methods of enrichment culture and sampling bacterial laccases from soil of industrial effluent treatment plant. In this study, soil samples were collected from the industrial effluent treatment plant. Other reports on the isolation of bacterial species showing laccase activity was carried out from rice rhizosphere, ${ }^{9}$ seawater, ${ }^{20}$ river sludge or top-soil containing organic litter, ${ }^{13}$ soil contaminated with dye and textile industry effluent and lignocellulosic wastes. ${ }^{30}$ In our study, the spore laccase was used for the decolorization of anthraquinone and azo dyes without nutrition or redox mediators. Our results indicated that the spore laccase could decolorize the dyes efficiently within 5 days. This result is similar to that of the spore laccase from Bacillus SF. ${ }^{4}$ However, few spore laccases could be reused, because it is difficult to separate spore laccase from the decolorized solution. The limitation reduces their utilization rate. Immobilized enzyme has high efficiency in dye decolorization, because immobilization can improve the utilization rate of enzyme despite the reducing enzyme activity. Our next efforts are to immobilize the spore laccases. The results demonstrate that spore laccase has potential application in dyestuff treatment. In summary, 
B. subtilis ETL-1979 exhibiting laccase activity was screened from soil of industrial effluent treatment plnat and is well characterized. The strain showed activity of catalyzing canonical laccase substrates, syringaldazine, good growth state at $55^{\circ} \mathrm{C}$, and its spore laccase could decolorize the most regular dyes efficiently without additional redox mediators.

\section{Acknowledgements}

None.

\section{Conflict of interest}

The author declares no conflict of interest.

\section{References}

1. Alexandre G, Zhulin LB. Laccases are widespread in bacteria. Trends Biotechnol. 2000;18(2):41-42.

2. D' Annibale A, Stazi SR, Vinciguerra V, et al. Oxirane-immobilized Lentinula edodes laccase: stability and phenolics removal efficiency in olive mill wastewater. J Biotechnol. 2000;77(2-3):265-273.

3. Ullah MA, Bedford CT, Evans CS. Reactions of pentachlorophenol with laccase from Coriolus versicolor. Appl Microbiol Biotechnol. 2000;53(2):230-234.

4. Held C, Kandelbauer A, Schroeder M, et al. Biotransformation of phenolics with laccase containing bacterial spores. Environ Chem Lett. 2005;3(2):74-77.

5. Witayakran S, Ragauskas AJ. Synthetic applications of laccase in green chemistry. Adv Synth Catal. 2009;351(9):1187-1209.

6. Steevensz A, Al-Ansari MM, Taylor KE, et al. Comparison of soybean peroxidase with laccase in the removal of phenol from synthetic and refinery wastewater samples. J Chem Technol Biotechnol. 2009;84(5):761769.

7. Younes SB, Mechichi T, Sayadi S. Purification and characterization of the laccase secreted by the white rot fungus Perenniporia tephropora and its role in the decolourization of synthetic dyes. $J$ Appl Microbiol. 2007;102(4):1033-1042.

8. Solano F, Lucas-Elio P, Lopez-Serrano D, et al. Dimethoxyphenol oxidase activity of different microbial blue multicopper proteins. FEMS Microbiol Lett. 2001;204(1):175-181.

9. Givaudan A, Effosse A, Faure D, et al. Polyphenol oxidase in Azospirillum lipoferum isolated from rice rhizosphere: evidence for laccase activity in non-motile strains of Azospirillum lipoferum. FEMS Microbiol Lett. 1993;108(2):205-210.

10. Diamantidis G, Effosse A, Potier P, et al. Purification and characterization of the first bacterial laccase in the rhizospheric bacterium Azospirillum lipoferum. Soil Biol Biochem. 2000;3(2000):919-927.

11. Claus H, Filip Z. The evidence of a laccase-like enzyme activity in a Bacillus sphaericus strain. Microbiol Res. 1997;152:209-216.

12. Grass G, Rensing C. CueO is a multi-copper oxidase that confers copper tolerance in Escherichia coli. Biochem Biophys Res Commun. 2001;286(5):902-908.
13. Ruijssenaars HJ, Hartmans S. A cloned Bacillus halodurans multicopper oxidase exhibiting alkaline laccase activity. Appl Microbiol Biotechnol. 2004;65(2):177-182.

14. Niladevi KN, Prema P. Immobilization of laccase from Streptomyces psammoticus and its application in phenol removal using packed bed reactor. World J Microbiol Biotechnol. 2008;24(7):1215-1222.

15. Hullo MF, Moszer I, Danchin A, et al. CotA of Bacillus subtilis is a copperdependent laccase. J Bacteriol. 2001;183(18):5426-5430.

16. Jimenez-Juarez N, Roman-Miranda R, Baeza A, et al. Alkali and halide-resistant catalysis by the multipotent oxidase from Marinomonas mediterranea. J Biotechnol. 2005;117(1):73-82.

17. Dube E, Shareck F, Hurtubise Y, et al. Homologous cloning, expression, and characterisation of a laccase from Streptomyces coelicolor and enzymatic decolourisation of an indigo dye. Appl Microbiol Biotechnol. 2008;79(4):597-603.

18. Sharma P, Goel R, Capalash N. Bacterial laccases. World J Microbiol Biotechnol. 2007;23(6):823-832.

19. Wang YL, Yang RH, Mao AJ, et al. Phylogenetic diversity analyse of Rumen Bacteria using culture independent method. Acta Microbiologica Sinica. 2005;45(6):915-919.

20. Solano F, Garcia E, Perez De Egea E, et al. Isolation and characterization of strain MMB-1 (CECT 4803), a novel melanogenic marine bacterium. Appl Environ Microbiol. 1997;6(9):3499-3506.

21. Xu F. Oxidation of phenols, anilines, and benzenethiols by fungal laccases: correlation between activity and redox potentials as well as halide inhibition. Biochemistry. 1996;35(23):7608-7614.

22. Manu B, Chaudhari S. Anaerobic decolorisation of simulated textile wastewater containing azo dyes. Bioresour Technol. 2002;82(3):225-231.

23. Jahmeerbacus MI, Kistamah N, Ramgulam RB. Fuzzy control of dyebath $\mathrm{pH}$ in exhaust dyeing. Coloration Technol. 2004;120(2):51-55.

24. Rensing C, Grass G. Escherichia coli mechanisms of copper homeostasis in a changing environment. FEMS Microbiol Rev. 2003;27(2-3):197-213.

25. Nakamura K, Go N. Function and molecular evolution of multicopper blue proteins. Cell Mol Life Sci. 2005;62(18):2050-2066.

26. Singh SK, Grass G, Rensing C, et al. Cuprous oxidase activity of CueO from Escherichia coli. J Bacteriol. 2004;186(22):7815-7817.

27. Outten FW, Huffman DL, Hale JA, et al. The independent cue and cus systems confer copper tolerance during aerobic and anaerobic growth in Escherichia coli. J Biol Chem. 2001;276(33):30670-30677.

28. Endo K, Hosono K, Beppu T, et al. A novel extracytoplasmic phenol oxidase of Streptomyces: its possible involvement in the onset of morphogenesis. Microbiology. 2002;148(Pt 6):1767-1776.

29. Sanchez-Amat A, Solano F. A pluripotent polyphenol oxidase from the melanogenic marine Alteromonas sp. share catalytic capabilities of tyrosinases and laccases. Biochem Biophys Res Commun. 1997;240(3):787792.

30. Senan RC, Abraham TE. Bioremediation of textile azo dyes by aerobic bacterial consortium: aerobic degradation of selected azo dyes by bacterial consortium. Biodegradation. 2004;15(4):275-280. 